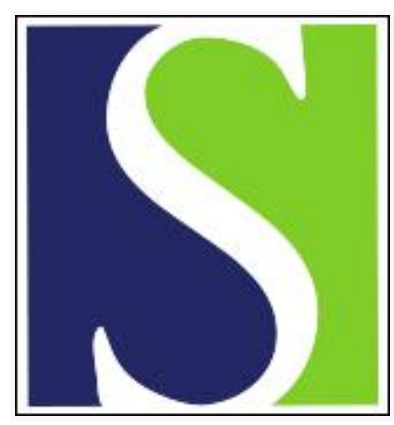

Scand J Work Environ Health 1998;24(4):245-254

https://doi.org/10.5271/sjweh.317

Issue date: Aug 1998

Biological effects of amplitude-modulated radiofrequency radiation

by Juutilainen J, de Seze R

Key terms: cellular telephone; electromagnetic fields; microwave; nonionizing radiation; nonthermal effect

This article in PubMed: www.ncbi.nlm.nih.gov/pubmed/9754855

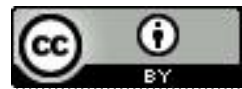




\title{
Biological effects of amplitude-modulated radiofrequency radiation
}

\author{
by Jukka Juutilainen, $P h D,{ }^{1}$ René de Seze, $P h D^{2}$
}

\begin{abstract}
Juutilainen J, de Seze R. Biological effects of amplitude-modulated radiofrequency radiation. Scand J Work Environ Health 1998;24(4):245-254.

Users of mobile telephones are exposed to radiofrequency radiation. One of the questions still open today is whether amplitude-modulated radiofrequency signals from digital phones exert specific bioeffects different from those of continuous (unmodulated) radiofrequency radiation. This paper reviews recent literature on the bioeffects of amplitude-modulated radiofrequency radiation, from cells to humans. The consistency of the results is discussed, and exposure parameters are compared to identify possible biologically active forms of amplitude modulation. Several studies have reported findings consistent with effects on the nervous system and cancer-related biological processes. However, the methods and exposure parameters vary widely, and no independent replications of the positive findings have been reported. The results available today fail to support the existence of well-defined modulation-specific bioeffects from exposure to radiofrequency radiation. Additional systematic studies are needed to identify possible reproducible modulation-dependent effects and biologically active modulation parameters.
\end{abstract}

Key terms cellular telephones, electromagnetic fields, microwaves, nonionizing radiation, nonthermal effects.

The bioeffects of amplitude-modulated (AM) radiofrequency radiation have been a subject of debate since early publications $(1,2)$ suggesting that weak radiofrequency radiation, if amplitude modulated at low frequencies, might have specific effects different from the thermal effects of strong radiofrequency energy. This discussion has been recently activated by the increasing human exposure to radiofrequency radiation due to the rapid growth in the use of mobile telephones.

Some of the new personal telecommunication systems emit AM radiofrequency electromagnetic fields. Since the modulation frequencies are in the extremely low-frequency $(\mathrm{ELF})$ range $(0-300 \mathrm{~Hz})$, it has been hypothesized that these modulated fields might have effects similar to the purported cancer-related or other health effects of ELF magnetic fields emitted by, for example, powerlines. Although the whole-body average exposure levels caused by these devices are very low, local energy absorption maximums can be close to the exposure limits. Moreover, the high number of people exposed warrants continued research to make sure that there are no risks associated with long-term exposure to weak AM fields.

This review focuses on recently published literature on the biological effects of AM radiofrequency radiation, from cells to humans. Reviews of the older literature are available elsewhere (3-6). The aim of this review is different from that of other recent reviews $(7,8)$. More than critically analyzing the details of each study, this paper attempts to address the consistency of the results with respect to the effective exposure parameters. If there are any specific effects of modulated radiofrequency radiation, it is important to try to identify the modulation frequencies, carrier frequencies, and other exposure parameters that are biologically active, as well as those that are not.

\section{Radiofrequency radiation}

Radiofrequency electromagnetic fields constitute a part of the electromagnetic spectrum (table 1). Microwaves are a part of the radiofrequency band. The limit between radiofrequency and infrared radiation is normally defined as $300 \mathrm{GHz}$, corresponding to a wavelength of $1 \mathrm{~mm}$. The lower frequency limit is variously defined by different organizations. In this review radiofrequency refers to frequencies above $100 \mathrm{kHz}$. In a strict physical sense, a radiofrequency electromagnetic field can be called radiofrequency radiation only in the far field (ie, far enough

1 Department of Environmental Sciences, University of Kuopio, Kuopio, Finland.

2 Laboratoire de Biophysique Médicale, Université de Montpellier I, Faculté de Médecine, Nimes, France.

Reprint requests to: Dr J Juutilainen, Department of Environmental Sciences, University of Kuopio, PO Box 1627, FIN-70211 Kuopio, Finland. [e-mail: jukka.juutilainen@uku.fi] 
Table 1. The electromagnetic spectrum.

\begin{tabular}{lcc}
\hline & Wavelength $(\lambda)^{\mathrm{a}}$ & Frequency $(f)^{\mathrm{a}}$ \\
\cline { 2 - 3 } & $<100 \mathrm{~nm}$ & $>3.10^{15} \mathrm{~Hz}$ \\
Ionizing radiation & $100-400 \mathrm{~nm}$ & $800-3000 \mathrm{THz}$ \\
Ultraviolet radiation & $400-700 \mathrm{~nm}$ & $400-800 \mathrm{THz}$ \\
Visible light radiation & $0.7-1 \mathrm{~mm}$ & $0.3-400 \mathrm{THz}$ \\
Infrared radiation & $1 \mathrm{~mm}-3 \mathrm{~km}$ & $0.1 \mathrm{MHz}-300 \mathrm{GHz}$ \\
Radiofrequency radiation & $1-1000 \mathrm{~mm}$ & $0.3-300 \mathrm{GHz}$ \\
Microwaves & $3-1000 \mathrm{~km}$ & $0.3-100 \mathrm{kHz}$ \\
Very low-frequency (VLF) & & \\
electromagnetic fields & $>1000 \mathrm{~km}$ & $<300 \mathrm{~Hz}$ \\
Extremely low-frequency (ELF) & $\infty$ & 0 \\
electromagnetic fields & $\infty$ & 0 \\
Static electric and magnetic fields & &
\end{tabular}

aThe relationship between wavelength and frequency is given by $c=\lambda f$, where $\mathrm{c}$ is the velocity of light (and other forms of electromagnetic radiation) in free space $\left(3 \cdot 10^{8} \mathrm{~m} / \mathrm{s}\right)$.

from the source). Normally, this means a distance of at least 1 wavelength. In nonphysical language, for example, in legislation, all forms of electromagnetic fields are sometimes called radiation even if they do not fulfill the physical criteria of electromagnetic radiation.

\section{Modulation}

Radiofrequency radiation is often modulated by another, lower frequency signal to make it, for example, carry information or to save energy. The most common forms of modulation used for telecommunication are amplitude modulation and frequency modulation. In amplitude

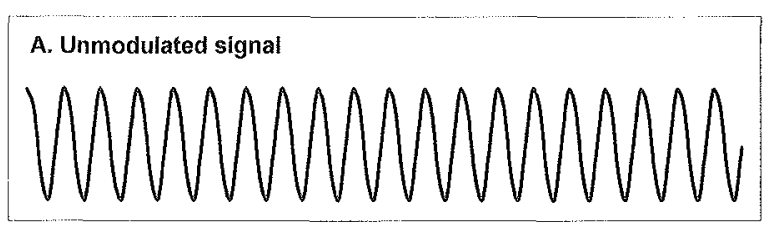

B. Amplitude modulation

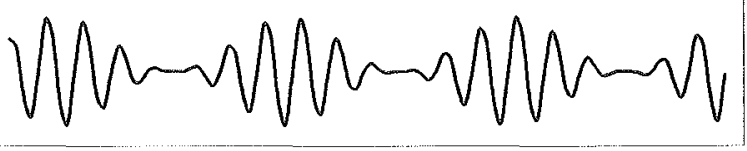

C. Pulse modulation

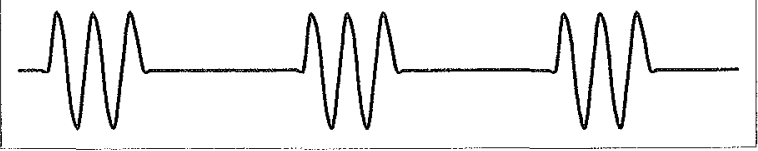

Figure 1. Schematic representation of an unmodulated (continuous) wave (A) and two forms of amplitude modulation: waves modulated with a smoothly varying $(B)$ or pulsed $(C)$ signal. modulation, the amplitude of the radiofrequency carrier wave is modulated by the low-frequency signal (eg, voice) (figure 1). Similarly, frequency modulation involves modulation of the frequency so that it varies in a narrow band around the basic frequency. A form of amplitude modulation is pulse modulation. Pulse-modulated $(\mathrm{PM})$ radiation with very high intensity, short duration pulses is emitted by radar. Pulse modulation is also used in digital mobile phones (9), such as the European GSM or the North American DAMPS system. The frequency of the pulses is $217 \mathrm{~Hz}$ with the GSM and $50 \mathrm{~Hz}$ with the DAMPS. Analog mobile phones, in contrast, are based on frequency-modulated (FM) signals.

\section{Thermal, athermal and nonthermal effects}

Absorbed radiofrequency energy is converted to heat in tissues. When the thermal load is such that the core temperature of the organism increases with respect to its normal value, "thermal" effects are induced. If the thermoregulatory system is able to maintain the organism at its normal temperature, "athermal" (or isothermal) effects may then be linked with chronic stress. Finally, when the thermal load is low enough not to trigger thermoregulation, "specific" or "nonthermal" effects can occur through mechanisms other than macroscopic heating of tissues.

Some of the bioeffects of pulsed fields that do not cause general heating or trigger thermoregulation may, nevertheless, be caused by local heat production. The hearing of microwave pulses is a good example. This generally accepted and physically well-understood phenomenon is based on thermoacoustic expansion, acoustic waves generated by the absorption of high-peak power microwave pulses (6). The hearing of microwave pulses can also produce behavioral changes in laboratory animals. Well-established specific bioeffects of AM radiofrequency radiation thus exist. However, the biological effects based on thermoacoustic expansion have not been included in this review. Instead the review focuses on the reported effects that may be "nonthermal", based on mechanisms other than tissue heating.

The amount of thermal energy absorbed per mass unit (watts/kilogram) is expressed by a quantity called specific absorption rate (SAR). It is recommended that the whole-body SAR values associated with human exposure to radiofrequency radiation should be less than $0.4 \mathrm{~W} /$ $\mathrm{kg}(10)$. The average SAR values of mobile phone users are orders of magnitude below this limit, but local maximums in the head can be higher than $1 \mathrm{~W} / \mathrm{kg}$ if calculated for very small volumes of tissue. This value is not far from the limit of $1.6 \mathrm{~W} / \mathrm{kg}$ (11) or $2 \mathrm{~W} / \mathrm{kg}$ (12) recommended for local exposure. 


\section{Effects of amplitude-modulated radiofrequency radiation in vitro}

\section{Nerve and muscle cells}

Many in vitro experiments have been performed on cardiac cells or isolated hearts. Microwaves were observed to affect aggregated cardiac cells from chicken embryos (13). Although a decrease in the interbeat interval after 190-second exposure to 2.45-GHz microwaves was consistent with a thermal effect, other results were less predictable, for example, an increase in the interbeat interval under continuous microwave exposure at $1.2-$ $12.2 \mathrm{~W} / \mathrm{kg}$ and a decrease in the interbeat interval after $\mathrm{PM}$ microwave exposures at 8.4-12.2 W/kg (duty cycle $=11 \%$ ). In contrast, although a higher average SAR of around $80 \mathrm{~W} / \mathrm{kg}$ was used $(2.45 \mathrm{GHz}, 10 \mu \mathrm{s}, 100 \mathrm{pps}$, $1 / 1000$ duty cycle), Field et al (14) did not find any effect on the mean action-potential firing rate of spontaneously active ganglion neurons of land snails, while a significant $(\mathrm{P}<0.05)$ increase in the mean input resistance of exposed neurons was described. Schwartz \& Mealing (15) did not find any change in calcium ion fluxes or contractile force in isolated atrial stripe of frog heart exposed for 32 minutes to continuous or AM 1-GHz electromagnetic fields $(0.5 \mathrm{~Hz}$ or $16 \mathrm{~Hz}, 3.2 \mu \mathrm{W} / \mathrm{kg}$ to $1.6 \mathrm{~W} / \mathrm{kg})$. Exposure of frog hearts for 2 hours to pulsed $2.45-\mathrm{GHz}$ microwaves $(10 \mu \mathrm{s}, 1 / 1000$ duty cycle, $16-\mathrm{Hz}$ modulation, SAR $0.003,2$ or $6 \mathrm{~W} / \mathrm{kg}$ ) did not modify conduction velocity (16). Although Pakhomov et al (17) did not find any effects on the twitch rates and amplitudes of isolated Rana temporaria frog auricles when PM 915-MHz microwaves at SAR values below $10-20 \mathrm{~W} / \mathrm{kg}$ were applied alone, they observed an increase in both these parameters after sensitization by $1-\mathrm{mM}$ caffeine added to the saline flow system.

\section{Genotoxicity}

An earlier critical review on the genotoxicity of microwave radiation in vitro (18) emphasized the need for careful temperature control and concluded that microwaves are not genotoxic unless high temperatures are achieved.

The possibility that genotoxic effects are induced after in vitro exposure to radiofrequency fields was investigated by D'Ambrosio et al (19) using human whole blood exposed to $9-\mathrm{GHz}$ microwaves amplitude modulated at $50 \mathrm{~Hz}(10 \mathrm{~min}, 90 \mathrm{~W} / \mathrm{kg})$. A marginally significant $(\mathrm{P}<0.05)$ increase in the number of cells showing micronuclei was seen after the AM exposure but not after the continuous exposure. The thermal increase was $5^{\circ} \mathrm{C}$, but the authors reported that a similar heating through a water bath had had no effects on micronuclei in earlier experiments.

Maes et al (20) exposed human peripheral blood lymphocytes to $2.45-\mathrm{GHz}$ microwaves for 30 and 120 minutes at a constant temperature of $36.1^{\circ} \mathrm{C}$. The authors found an increase in the frequency of chromosome aberrations and micronuclei. However, cell proliferation and sister chromatid exchange frequency were not affected. In a recent study by the same group (21), whole blood was exposed next (5-cm distance) to the radiating antenna of a GSM base station (49-V/m, 2-h exposure). Although some genetic damage was observed (chromosome aberrations), the authors concluded that microwaves emitted by a base station are not capable of inducing genetic effects in the general population exposed to field levels much lower than those used in these experiments.

The clastogenic effects of short-wave exposure (10$21 \mathrm{MHz}$ ) were tested using plant cuttings (Tradescantia) exposed in situ near various broadcasting antennas for 30 hours (22). There was a statistically significant 2 -fold increase in the mean micronuclei frequency in the exposed samples with respect to sham-exposed (shielded) or control (100 $\mathrm{m}$ away) samples. The effect occurred at field levels of $27.5 \mathrm{~V} / \mathrm{m}$ and $0.073 \mathrm{~A} / \mathrm{m}$, that is, at levels which should not cause any significant heating of the samples.

\section{Studies related to cocarcinogenic effects}

Genetic mutation is the first step of carcinogenesis, often called initiation. Promoters are agents that act during the later stages of carcinogenesis, leading to the development of tumors from the initiated potential cancer cells. Carcinogenesis is a complex process, and several different factors may modify the probability that genotoxic effects lead to the development of malignant tumors. The term cocarcinogenic is used here to refer to promoters and other agents that are carcinogenic only in combination with genotoxic exposures.

Combined effects of 954-MHz radiofrequency radiation and the chemical mutagen mitomycin $\mathrm{C}$ were studied using sister chromatic exchange in human lymphocytes as the end point (23). Whole blood samples from 8 donors were exposed to AM radiation from a GSM base station. The samples were kept $5 \mathrm{~cm}$ away from the antenna at a constant temperature of $17( \pm 1)^{\circ} \mathrm{C}$. The estimated SAR was $1.5 \mathrm{~W} / \mathrm{kg}$. After the radiofrequency exposure, lymphocytes were cultured for 70 hours with or without mitomycin $\mathrm{C}$. The radiofrequency exposure alone did not increase the frequency of sister chromatid exchanges. However, a clear increase was seen in the cells exposed to mitomycin $\mathrm{C}$, and this response was significantly enhanced in the cells exposed to microwaves.

Cain et al (24) tested the hypothesis that AM microwaves and a chemical tumor promoter, 12-O-tetradecanoylphorbol-13-acetate (TPA), are copromoters that enhance focus formation of transformed cells in coculture with parental C3H/10T1/2 fibroblasts. In this model, the parental cells normally suppress focus formation, 
probably due to intercellular communication between the transformed cells and normal cells. Decreased intercellular communication is probably the main mechanism by which tumor promoters lead to focus formation in this model. Cell cultures were exposed to an $836.55-\mathrm{MHz}$ field using a form of pulse modulation [time-division multiple access (TDMA)] with a pulse frequency of $50 \mathrm{~Hz}$. An SAR value of $0.15,1.5$, or $15 \mathrm{~mW} / \mathrm{kg}$ was used during the pulses. The cells were exposed 24 hours a day for 28 days in a repeating cycle, 20 minutes on, 20 minutes off. The radiofrequency exposures did not alter the TPA-induced focus formation in this model.

Ornithine decarboxylase (ODC) is an enzyme needed in the synthesis of polyamines. Its activity is elevated in rapidly growing tissues, including tumors. ODC activity is also strongly increased by known chemical tumor promoters such as TPA, and it is therefore a potentially useful marker of tumor promotion. Both ELF magnetic fields $(25,26)$ and AM microwaves $(27)$ have been reported to affect ODC activity in vitro and in vivo, although the about 2-fold increases found in these experiments are much lower than the changes induced by, for example, TPA. The role of different modulations in the effects of 835-MHz microwaves on the activity of ODC was investigated in L929 cells at an SAR of about $2.5 \mathrm{~W} / \mathrm{kg}(28)$. Exposure to continuous waves produced no effects for exposure times between 2 and 24 hours, except for a small enhancement after 6 hours of exposure. No effects were seen in cells exposed to FM signals. Exposure to AM fields, in contrast, yielded significant enhancement of ODC activity. The effect was seen at several different types of amplitude modulation, including a typical signal from a TDMA cellular telephone. The effect was frequency dependent, with statistically significant effects at modulation frequencies from 16 to $65 \mathrm{~Hz}$, but little or no effects at $6 \mathrm{~Hz}$ and $600 \mathrm{~Hz}$.

\section{Effects of amplitude-modulated radiofrequency radiation in vivo}

\section{Nervous system}

Lai (29) published an extensive review of the neurological effects of radiofrequency radiation, from the ionic or molecular level (calcium fluxes, neurotransmitters, etc) to the behavioral level (psychological effects), including anatomy, morphology, physiology, electrophysiology, and interactions with drugs. In recent years, many experiments conducted by Lai and his co-workers on neurochemical changes showed effects of acute low-level microwave radiation on the neurological system of rats, particularly modifying the pharmacologic action of drugs on phenomena such as hypo- or hyperthermia, catalepsy, stereotypic behavior, and narcosis (30). Additional effects were seen independently of any drug on the activity of the cholinergic system in rat brain, functionally related to behavioral tasks involving learning and memory. Activation of endogenous opioids by microwaves seemed to play an important mediating role in some of these effects. Recent results by Lai indicate an important role for the cholinergic system and endogenous opioids in the microwave-induced spatial memory deficit in the radial-arm maze (31). These results suggest that the effect of microwaves on working memory also involves the cholinergic system, also modulated by endogenous opioids, and moreover that only central, and not peripheral, endogenous opioids are responsible for the effect. According to the authors, the septohippocampal pathway was much more involved in the acute effect of microwaves than the basalis-cortical pathway was.

Another effect on the cholinergic system was reported for $880-\mathrm{MHz}$ microwaves pulse-modulated with 16 $\mathrm{Hz}$ square waves (32). A 1-hour exposure of male Wistar rats significantly decreased acetylcholinesterase activity in the neocortex by $25 \%$. This effect was not obtained at other modulation frequencies $(3,5,7$ or $30 \mathrm{~Hz})$ or with unmodulated continuous waves. The gammaaminobutyric acid (GABA) and glutamate receptors were also affected after exposures as short as 5 minutes, at $880 \mathrm{MHz}$ or $915 \mathrm{MHz}$, with a decrease in ${ }^{3} \mathrm{H}$-muscimol binding and an increase in ${ }^{3} \mathrm{H}$-glutamate. This effect was dose-dependent for power densities greater than $50 \mu \mathrm{W} / \mathrm{cm}^{2}$. In vitro studies on synaptosomal preparations or a model system consisting of a bilayer proteolipid membrane enriched in GABA receptors yielded similar results.

Consistent behavioral and endocrine changes were observed under various conditions of exposure to lowintensity $3-\mathrm{GHz}$ continuous or $2.45-\mathrm{GHz}$ modulated microwaves (33). The modulation consisted of pulse trains, with a pulse frequency of $400 \mathrm{~Hz}$ within each train, and the repetition frequency of the trains was $0.05,0.28$, or $0.5 \mathrm{~Hz}$. The effect was different (activation or inhibition) depending on the duration of exposure: $0.5-12$ hours, single or repeated ( $15-60$ days, $7-12$ hours/day), pulsed or continuous wave exposure. A threshold level was determined at $10 \mu \mathrm{W} / \mathrm{cm}^{2}$.

No effects of continuous-wave microwaves at $10 \mu \mathrm{W} / \mathrm{cm}^{2}$ were found on the total power of the electroencephalographic (EEG) spectrum from rats (34). However, an increase in the delta band and a decrease of the alpha and beta bands were observed after a 5-minute exposure to $2.45-\mathrm{GHz}$ pulsed microwaves at $3 \mu \mathrm{W} / \mathrm{cm}^{2}$ ( $217 \mathrm{~Hz}, 1 / 8$ duty cycle) (35).

Three-hour whole-body irradiation at an incident power density of $1 \mu \mathrm{W} / \mathrm{cm}^{2}$ to $2450-\mathrm{MHz}$ microwaves amplitude modulated at $16 \mathrm{~Hz}$ caused changes in the ultrastructural distribution of calcium and calcium- 
activated ATPase (adenosine triphosphatase) in the medial habenula of mice (36). The changes included a decreased number of synaptic vesicles containing $\mathrm{Ca}^{++}$precipitates at 1 hour and 24 hours after exposure, appearance of reaction products in the synaptic clefts and on nonsynaptic surfaces of the neuronal plasma membrane, and increased $\mathrm{Ca}^{++}$-ATPase activity, specific for quercetin-sensitive intracellular $\mathrm{Ca}^{++}$-ATPase.

\section{Human experiments}

The effects of pulsed high-frequency electromagnetic fields similar to those emitted by mobile telephones were recently published in relation to human sleep (37). The power density was low $\left(50 \mu \mathrm{W} / \mathrm{cm}^{2}\right)$ and thus mimicked exposure to a nearby base station. It was applied for 8 hours starting at light extinction at 2300 . Twelve subjects spent 3 successive nights in a sleep laboratory. The first night was for adaptation, and during the 2 following nights they were either exposed or sham exposed. The significant findings included a decrease in sleep onset latency, from $12.3( \pm 6.0)$ to $9.5( \pm 4.4)$ minutes, and a slight alteration, from $-10.1( \pm 1.4)$ to $-9.6( \pm 1.6) \mathrm{dB}[0$ $\left.\mathrm{dB}=1(\mu \mathrm{V})^{2} / \mathrm{Hz}\right]$, of the mean power density of the averaged power EEG spectrum during REM (rapid eye movement) sleep. Exposure of awake subjects for 3.5 minutes to the same field did not cause any changes in the electroencephalogram (38).

\section{Blood-brain barrier}

An important characteristic of the central nervous system is the permeability of the blood-brain barrier. Exposure of Fischer 344 rats to $915-\mathrm{MHz}$ microwaves at SAR values between 0.016 and $5 \mathrm{~W} / \mathrm{kg}$ showed significantly more albumin leakage in animals exposed to PM (30\%) or continuous fields $(40 \%, \mathrm{P}=0.002)$ than in control animals $(8 \%)(39-41)$. Similar findings were reported by another group (42) for rats exposed to the radiofrequency, static or gradient magnetic fields associated with magnetic resonance imaging.

\section{Genotoxic effects}

When evaluated by the alkaline microgel electrophoresis ("comet") assay, acute exposure of rats to low-intensity microwaves increased DNA (deoxyribonucleic acid) single- and double-strand breaks in brain cells $(43,44)$. Male Sprague Dawley rats were exposed for 2 hours to pulsed microwaves $(2.45 \mathrm{GHz}, 2-\mu$ s pulse width, 500 pps, SAR of 0.6 or $1.2 \mathrm{~W} / \mathrm{kg}$ ) or continuous microwaves (SAR of $1.2 \mathrm{~W} / \mathrm{kg}$ ). Four hours after the pulsed exposure, the number of DNA breaks was statistically significantly increased. In the continuous exposure the increase was detectable immediately after the 2-hour exposure. The mechanism behind these observations is not known. The authors speculated on a possible increase in DNA breakage or a suppression of the repair processes.

\section{Life span and cancer studies}

An extensive review of long-term exposure of animals to radiofrequency radiation was written by Guy (45). Another review (46) indicated a trend towards an increase rather than a decrease in life span. Chou et al (47) exposed 100 male Sprague-Dawley rats for 25 months, 21.5 hours/day, to $2.45-\mathrm{GHz}$ microwaves pulse modulated at $800 \mathrm{~Hz}$. The pulsed microwaves were square-wave modulated at $8 \mathrm{~Hz}$. The SAR values ranged from 0.4 to $0.15 \mathrm{~W} / \mathrm{kg}$ depending on animal weight. The general health of the animals was evaluated by measuring several parameters, including behavior, immunology, hematology, blood chemistry, metabolism, organ weights, histopathology, and longevity. The total number of end points was 155 . The findings were negative for most of the parameters measured. Positive findings of effects on corticosterone levels and the immune system at 13 months of exposure were not confirmed in follow-up studies. Differences in oxygen consumption and carbon dioxide production were seen in young rats. A statistically significant increase of primary malignant tumors was observed in the exposed versus the control rats. The authors concluded that the results did not indicate any definitive biological effects in rats chronically exposed to radiofrequency radiation at $2.45 \mathrm{GHz}$. The positive findings need independent experimental evaluation.

Transgenic mice of the strain E $\mu$-Piml were exposed to $900-\mathrm{MHz}$ radiofrequency fields pulse modulated at $217 \mathrm{~Hz}$, similar to the fields used in GSM phones (48). Eu-Pinl mice are moderately predisposed to develop lymphoma spontaneously. One hundred animals were exposed and 101 were sham-exposed for 60 minutes a day for 18 months. The specific absorption rates varied from 0.008 to $4.2 \mathrm{~W} / \mathrm{kg}$. A statistically significant doubling of lymphoma risk was found for the exposed mice in a comparison with the controls.

A study on the progression of transplanted brain tumors (49) failed to find any effects of continuous or pulsed microwaves. Several modulations were tested, including the $217-\mathrm{Hz}$ modulation of GSM mobile phones.

Female Sprague-Dawley rats $(\mathrm{N} 1=21)$ received an injection of benzo[a]pyrene and were divided into 8 groups (50). The animals were then sham-exposed or exposed 2 hours/day to pulsed, GSM-type $(217 \mathrm{~Hz}$, duty factor $1 /$ 8) $900-\mathrm{MHz}$ microwaves at 55 or $200 \mu \mathrm{W} / \mathrm{cm}^{2}$. The estimated SAR values were 0.065 or $0.24 \mathrm{~W} / \mathrm{kg}$. No differences were seen in tumor development, the level of an autoantibody related to tumor development, survival, or immunologic parameters.

\section{Epidemiologic studies}

Very little epidemiologic evidence is available on AM radiofrequency electromagnetic fields $(51,52)$. Most of 
these studies deal with radioelectronics workers or with radar- or radio-broadcasting exposure.

Slight changes in the heart rate of radiocommunications workers have been reported $(53,54)$ that suggest neurovegetative impairment due to radiofrequency exposure. The small size of the cohort ( 71 exposed persons, 22 referents) indicates that confirmation with a more extensive study is needed. Similar findings were recently published from an old study (1973-1975) using a threshold of $100 \mathrm{~V} / \mathrm{m}$ between the high- and low-level exposures (55). Neurovegetative disturbances without focal central nervous system (CNS) changes were also found by Bielski (56), with abnormal EEG recordings from $29 \%$ of the workers.

The population of the Skrunda village in Latvia has been chronically exposed to PM radiofrequency radiation from a near-by radio station. The station consists of 2 radars operating in the $156-$ to $162-\mathrm{MHz}$ range. They emit 0.8 -ms pulses at $41-\mathrm{ms}$ intervals (ie, the pulse frequency is $24.4 \mathrm{~Hz}$ ). The time-average exposure levels did not exceed $100 \mu \mathrm{W} / \mathrm{cm}^{2}$ (57), but no detailed assessment of the radiofrequency levels experienced by the "exposed" population is available. Significant differences in motor function, memory, and attention were reported in an epidemiologic study comparing schoolchildren living in the exposed area and in a nearby reference area (58).

All cancer cases among Polish military career personnel were registered during a period of 15 years (59). Each year about $3700(3 \%)$ of the population were classified as exposed to radiofrequency radiation. Data on exposure was obtained from military safety groups, who take measurements of radiofrequency intensities around potential sources and keep health records of personnel working at these posts. The radiofrequency exposures were mostly pulse-modulated and had carrier frequencies of $150 \mathrm{MHz}-3.5 \mathrm{GHz}$. At about $80 \%$ of the posts, the intensities were $0.1-2 \mathrm{~W} / \mathrm{m}^{2}$. About $15 \%$ had intensities of $2-6 \mathrm{~W} / \mathrm{m}^{2}$, and exposure exceeding $6 \mathrm{~W} / \mathrm{m}^{2}$ was rare. Compared with the unexposed personnel, the risk for all cancers was twice as high [relative risk (RR) 2.07, $95 \%$ confidence interval (95\% CI) $1.1-3.6]$ among those exposed to radiofrequency radiation. The increase was mainly due to increased colorectal (RR 3.2, 95\% CI 1.56.2) malignancies, esophagus and stomach (RR 3.2, 95\% CI 1.9-5.1) malignancies, nervous system tumors (RR $1.9,95 \% \mathrm{CI} 1.1-3.5)$, and malignancies of the hematopoietic system and lymphatic organs (RR 6.3, 95\% CI $3.1-14.3$ ).

An association between lung cancer and exposure to "pulsed electromagnetic fields" among electric utility workers has been reported (60). The odds ratio for all cancers was also slightly increased in the highest exposure category. The exposure was evaluated by the radiofrequency channel of personal electromagnetic exposure meters (Positron). The radiofrequency channel has been designed to detect fast-changing transients from 50 - to $60-\mathrm{Hz}$ electrical systems by measuring fields in the 5 - to 20-MHz frequency band. It was later, however, found to respond to other frequencies, including transmissions from walkie-talkies and car and truck radios. The interpretation of these findings is difficult because it is not exactly known what the meters actually measured.

The AM electromagnetic fields emitted by the Skrunda station and the Polish military (mainly radar) equipment differ in many respects from those produced by mobile phones. As long as we do not understand the mechanisms of the possible bioeffects of AM radiofrequency radiation, the observations are of limited value in assessing the health effects of mobile communication.

Mobile phones have been used only for a relatively short period. Epidemiologic studies on the eventual health effects related to these devices are starting, and only short-term results are now available (61).

\section{Mechanisms of interaction}

There is no generally accepted theory to explain the biophysical mechanisms by which AM fields could affect living organisms unless they are strong enough to cause general or local heating. Any theory that attempts to answer this question should explain the basic physical processes by which cells detect weak signals. If the biological responses are due to the modulation frequency and not the carrier frequency, the theory should also explain how the radiofrequency signal is demodulated to produce the low-frequency signal. Many hypothetical mechanisms have been proposed $(6,62,63)$. Most of the proposed mechanisms are merely qualitative speculations that cannot be verified or falsified by experimental testing. These are of little, if any, value in understanding the biophysical basis of the possible effects of modulated radiofrequency radiation. Some of the hypotheses, however, have been formulated exactly enough to produce predictions that can be tested experimentally.

As long as the interaction mechanisms remain unknown, it will be difficult to accept the existence of specific bioeffects of AM radiofrequency fields.

\section{Discussion}

Results suggesting bioeffects of weak AM radiofrequency fields have been obtained using a wide variety of biological models and end points. None of the findings described in this review have been replicated in an independent laboratory. Thus they cannot be considered as established bioeffects. 
Table 2. Recent studies of the biological effects of amplitude-modulated radiofrequency radiation. [CF $=$ carrier frequency, $M F=$ modulation frequency, $\mathrm{SAR}=$ specific absorption rate, $\mathrm{CW}=$ continuous wave, $\mathrm{AM}=$ amplitude modulation, $\mathrm{AchE}=$ acetylcholinesterase, $\mathrm{GABA}=$ gamma-aminobutyric acid, $\mathrm{EEG}=$ electroencephalography, ATPase $=$ adenosine triphosphatase,$+=$ an effect has been observed, $++=$ stronger effect than at the other exposure parameters, $+d=$ the effect differs from those of the other field parameters, but it is not possible to say which effect is stronger (eg, different direction of change), " = no effect, .. = data not available]

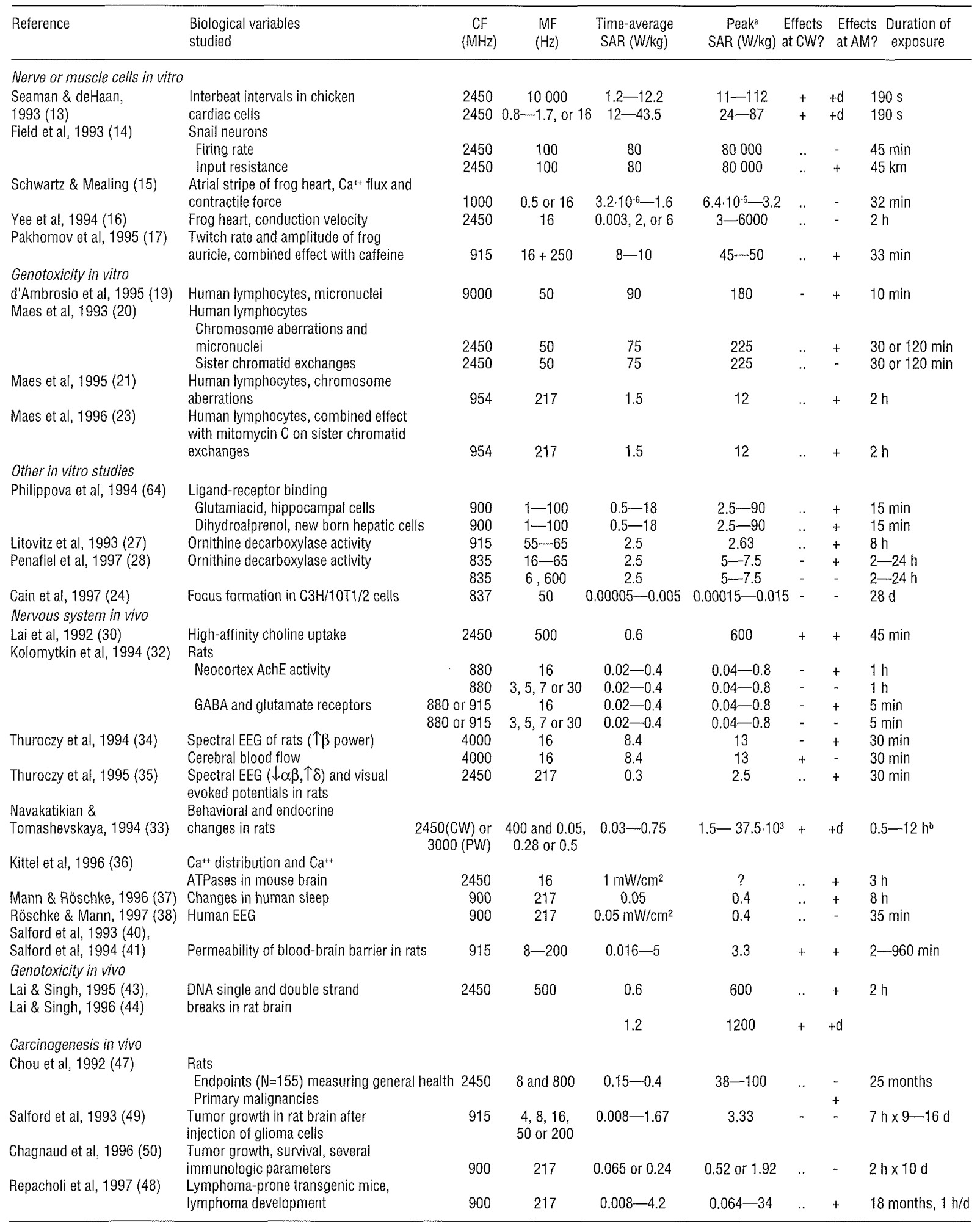

a For pulsed modulations the peak value is here defined as the SAR or intensity during the pulse, and it has been calculated for this table as the time-average value (usually given in the original article) divided by the duty cycle. For $100 \%$ sinusoidal modulations, the peak value has been calculated as twice the average.

S Single or repeated (15-60 d, $7-12 \mathrm{~h} / \mathrm{d})$. 
The varying biological models and methods make it difficult to form a unified picture of the possible bioeffects of AM radiofrequency radiation. Genotoxic effects have been reported at relatively low $S A R$ values both in vivo and in vitro. However, the whole animal models used thus far have not provided clear evidence of cancer-related effects of radiofrequency radiation. There is also some evidence that relatively weak AM fields may affect behavior and functioning of the nervous system in vivo, but there is only limited in vitro support for the effects of weak fields on nerve or muscle cells.

To evaluate the consistency of the results, the exposure parameters found to affect or not to affect organisms in recent studies are compared in table 2 on page 251.

If there are specific biological effects that depend on the low-frequency signal used for modulating the radiofrequency carrier wave, rectification or demodulation of the carrier wave must take place in cells or tissues. The speed of the demodulation mechanism sets an upper limit for the frequency of the carrier wave that can be demodulated. The data available in table 2 are very limited for evaluating the possible dependence of the effects on carrier frequency. Carrier frequencies of $2.45 \mathrm{GHz}$ or around $900 \mathrm{MHz}(880-1000 \mathrm{MHz})$ have been used in most of the studies. Effects at relatively low SAR values have been reported at both frequencies, although there is a tendency towards the use of high SAR values or, if the timeaveraged SAR is low, very high peak SAR values in experiments conducted using the $2.45-\mathrm{GHz}$ carrier frequency $(31,43,44)$. In the only study at $9 \mathrm{GHz}(19)$, a high time-averaged SAR of $90 \mathrm{~W} / \mathrm{kg}$ was used.

Although several hypothetical mechanisms have been proposed to explain the effects of weak ELF fields or ELF-modulated radiofrequency fields, there is no generally accepted biophysical theory that would predict which modulation frequencies do and which do not produce biological effects. Neither do the studies reviewed in table 2 suggest a clear dependence on modulation frequency. Effects have been reported at several frequencies, mostly below $1000 \mathrm{~Hz}$. However, comparing the effects of different frequencies is difficult, as most studies have used only one modulation frequency. Two studies that tested several frequencies did not find indications of frequency dependency $(40,64)$. Seaman \& deHaan (13) found effects at all modulation frequencies, but there were some indications that different modulations might act differently. Kolomytkin et al (32) saw a response at the $16-\mathrm{Hz}$ modulation frequency, but no effects at $3,5,7$ or $30 \mathrm{~Hz}$. The results of Penafiel et al (28) indicate that there might be a range of modulation frequencies from 16 to $65 \mathrm{~Hz}$ that are biologically active, while no significant effects have been observed at $6 \mathrm{~Hz}$ or $600 \mathrm{~Hz}$. Navakatikian \& Tomashevskaya (33) always used $400-\mathrm{Hz}$ modulation within the pulse trains, but their results indicate that the repetition frequency $(0.05$ to $0.5 \mathrm{~Hz})$ of the pulse trains might be of importance for the biological effects. From a practical point of view, it is worth noting that effects at relatively low SAR values have also been reported at 217 and $50-60 \mathrm{~Hz}$, frequencies common in the human environment.

Many studies have used only AM exposure. Whether the effects reported in these studies depend on the presence of the modulation is not known. Three studies (19, 28,32 ) report effects with amplitude modulation but not with continuous radiation, and 4 studies report different effects with continuous and AM exposures (13, 33, 34, 43).

\section{Concluding remarks}

The literature relevant to the possible specific biological effects of AM radiofrequency radiation consists of scattered observations obtained using a wide variety of experimental models and exposure parameters. The results available today do not form an internally consistent picture that would point to the existence of well-defined biological effects at certain physical parameters of AM radiofrequency radiation.

A more systematic approach in bioeffects research is needed for the risk assessment of AM radiofrequency radiation. Since any single study can answer only a very limited number of questions, a systematic approach is best achieved by increased international collaboration and the coordination of research efforts.

To study the existence of modulation-dependent effects, further studies should always include both modulated- and continuous-wave exposure groups. If reproducible effects are found, additional studies should investigate the dependence of the effects on modulation and carrier frequencies.

\section{References}

1. Bawin SM, Gavalas-Medici RJ, Adey WR. Reinforcement of transient brain biorhythms by amplitude-modulated VHF fields. In: Llaurado JG, Sances A, Battocletti JH, editors. Biological and clinical effects of low frequency magnetic and electric fields. Springfield (IL): Charles C Thomas, 1975:172.

2. Blackman CF, Elder JA, Weil CM, Benane SG, Eichinger DC, House DE. Induction of calcium ion efflux from brain tissue by radiofrequency radiation: effects of modulation, frequency and field strength. Radio Sci 1979;14:93-8.

3. McKinlay AF, Allen SG, Dimbylow PJ, Muirhead CR, Saunders RD. Restrictions on human exposure to static and time varying electromagnetic fields and radiation: scientific basis and recommendations for the implementation of the Board's statement. Didcot: National Radiological Protection Board 
(NRPB), 1993. Documents of the NRPB 4.

4. World Health Organization (WHO). Electromagnetic fields $(300 \mathrm{~Hz}$ to $300 \mathrm{GHz})$. Geneva: WHO, 1993. Environmental health criteria 137.

5. Polson P, Heynick LN. Overview of the RF radiation bioeffects database. In: Klauenberg BJ, Grandolfo M, Erwin DN, editors. Radiofrequency radiation standards, biological effects, dosimetry, epidemiology, and public health policy. New York (NY): Plenum Press, 1995. Nato ASI series. Series A: life sciences 274:311-26.

6. Postow E, Swicord ML. Modulated fields and "window" effects. In: Polk C, Postow E, editors. CRC handbook of biological effects of electromagnetic fields. Boca Raton (FL): CRC Press, 1996:535-81.

7. Verschaeve L, Maes A. Genetic, carcinogenic and teratogenic effects of radiofrequency fields. Mutat Res. In press.

8. Juutilainen J, Lang S. Genotoxic, carcinogenic and teratogenic effects of electromagnetic fields: introduction and overview. Mutat Res 1997;387:165-71.

9. Pedersen GF. Amplitude modulated RF fields stemming from a GSM phone. In: Simunic D, editor. Biological effects relevant to amplitude modulated RF fields: proceedings of the COST 244 workshop, September 1995, Kuopio. European Union, 1996:55-65. CEC-XIII-244/6/96.

10. International Radiation Protection Association (IRPA). Guidelines on limits of exposure to radiofrequency electromagnetic fields in the frequency range from $100 \mathrm{kHz}$ to $300 \mathrm{GHz}$. Health Phys 1988;54:115-23.

11. Institute of Electrical and Electronic Engineers (IEEE). Standard for safety levels with respect to human exposure to radiofrequency electromagnetic fields, $3 \mathrm{kHz}$ to $300 \mathrm{GHz}$. New York (NY): IEEE, 1992. IEEE C95.1-1991.

12. International Commission on Non-Ionizing Radiation Protection (ICNIRP). Health issues related to the use of hand-held radiotelephones and base transmitters. Health Phys 1996;70:587-93.

13. Seaman RL, deHaan RL. Inter beat intervals of cardiac cell aggregates during exposure to $2.45-\mathrm{GHz} \mathrm{CW}$, pulsed and square wave modulated microwaves. Bioelectromagnetics 1993; $14: 41-55$.

14. Field AS, Ginsburg K, Lin JC. The effect of pulsed microwaves on passive electrical properties and interspike intervals of snail neurons. Bioelectromagnetics 1993;14:503-20.

15. Schwartz JL, Mealing GAR. Calcium ion movement and contractility in atrial strips of frog heart are not affected by low frequency modulated, $1-\mathrm{GHz}$ electromagnetic radiation. Bioelectromagnetics 1993;14:521-33.

16. Yee KC, Chou CK, Guy AW. Character of the effect of microwave on conduction velocity of frog ventricular muscle. Bioelectromagnetics 1994;15:555-61.

17. Pakhomov AG, Dubovick BV, Degtyariov IG, Pronkevich AN. Microwave influence on the isolated heart function, II: combined effect of radiation and some drugs. Bioelectromagnetics 1995;16:250 - 4 .

18. Meltz ML. Biological effects versus health effects: an investigation of the genotoxicity of microwave radiation. In: Klauenberg BJ, Grandolfo M, Erwin DN, editors. Radiofrequency radiation standards: biological effects, dosimetry, epidemiology, and public health policy. New York (NY): Plenum Press, 1995:235-41. Nato ASI series. Series A: life sciences 274.

19. d'Ambrosio G, Lioi MB, Massa R, Scarfi MR, Zeni O. Genotoxic effects of amplitude-modulated microwaves on human lymphocytes exposed in vitro under controlled conditions. Electro Magnetobiol 1995;14:157-64.
20. Maes A, Verschaeve L, Arroyo A, Dewagter C, Vercruyssen L. In vitro cytogenetic effects of $2450 \mathrm{MHz}$ waves on human peripheral blood lymphocytes. Bioelectromagnetics 1993;14:495-501.

21. Maes A, Collier M, Slaets D, Verschaeve L. Cytogenetic effects of microwaves from mobile communication frequencies (954 MHz). Electro Magnetobiol 1995:14:91 - 8.

22. Haider T, Knasmueller S, Kundi M, Haider M. Clastogenic effects of radiofrequency radiations on chromosomes of tradescantia. Mutat Res 1994:324:65-8.

23. Maes A, Collier M, Slaets D, Verschaeve L. $954 \mathrm{MHz}$ microwaves enhance the mutagenic properties of mitomycin $\mathrm{C}$. Environ Mol Mutagen 1996;28:26-30.

24. Cain C, Thomas DL, Adey WR. Focus formation of C3H/ $10 \mathrm{~T} 1 / 2$ cells and exposure to a $836.55 \mathrm{MHz}$ modulated radiofrequency field. Bioelectromagnetics 1997;18:237-43.

25. Litovitz TA, Krause D, Mullins JM. Effect of coherence time of the applied magnetic field on ornithine decarboxylase activity. Biochem Biophys Res Comm 1991;178:862-5.

26. Mevissen M, Kiezmann M, Löscher W. In vivo exposure of rats to a weak alternating magnetic field increases ornithine decarboxylase activity in the mammary gland by a similar extent as the carcinogen DMBA. Cancer Lett 1995;90:20714.

27. Litovitz TA, Krause D, Penafiel M, Elson EC, Mullins JM. The role of coherence time in the effect of microwaves on ornithine decarboxylase activity. Bioelectromagnetics 1993:14:395-403.

28. Penafiel ML, Litovitz T, Krause D, Desta A, Mullins JM. Role of modulation on the effect of microwaves on ornithine decarboxylase activity in L929 cells. Bioelectromagnetics 1997; 18:132-41.

29. Lai H. Neurological effects of radiofrequency electromagnetic radiation. In: Lin JC, editor. Advances in electromagnetic fields in living systems, vol 1. New York (NY): Plenum Press, 1994:27-80.

30. Lai $\mathrm{H}$. Research on the neurological effects of nonionizing radiation at the University of Washington. Bioelectromagnetics 1992;13:513-26.

31. Lai H, Horita A, Guy AW. Microwave irradiation affects radial arm maze performance in the rat. Bioelectromagnetics $1994 ; 15: 95-104$.

32. Kolomytkin O, Kusnetsov V, Yurinska M, Zharikov S, Zharikova $A$. Response of brain receptor systems to microwave energy exposure. In: Frey A, editor. On the nature of electromagnetic field interactions with biological systems. Austin (TX): RG Landes, 1994:194 206.

33. Navakatikian MA, Tomashevskaya LA. Phasic behavioral and endocrine effects of microwaves of nonthermal intensity. In: Carpenter DO, Ayrapetyan S, editors. Biological effects of electric and magnetic fields; vol 1. San Diego (CA): Academic Press, 1994:333-42.

34. Thuroczy G, Kubinyi G, Bodo M, Bakos J, Szabo LD. Simultaneous response of brain electrical activity (EEG) and cerebral circulation (REG) to microwave exposure in rats. Rev Environ Health 1994;10:135-48.

35. Thuroczy G, Kubinyi G, Nagy N, Szabo LD. Measurements of visual evoked potentials (VEP) and brain electrical activity (EEG) after GSM-type modulated microwave exposure on rats. In: Honma T, editor. Advanced computational electromagnetics. Amsterdam: Elsevier/IOS Press, 1995:384-95.

36. Kittel A, Siklos L, Thuroczy G, Somosy Z. Qualitative enzyme histochemistry and microanalysis reveals changes in ultrastructural distribution of calcium and calcium-activated 
ATPases after microwave irradiation of the medial habenula. Acta Neuropathol 1996;92(4):362-8.

37. Mann K, Röschke J. Effects of pulsed high-frequency electromagnetic fields on human sleep. Neuropsychobiology 1996;33:41-7.

38. Röschke J, Mann K. No short-term effects of digital mobile radio telephone on the awake human electroencephalogram. Bioelectromagnetics 1997;18:172-6.

39. Persson BRR, Salford LG. Permeability of the blood-brain barrier in rats induced by continuous wave and pulse-modulated $915 \mathrm{MHz}$ electromagnetic radiation exposure in TEMcells. In: Simunic D, editor. Biological effects relevant to amplitude modulated RF fields: proceedings of the COST 244 workshop; September 1995, Kuopio. European Union, 1996:66-72. CEC-XIII-244/6/96.

40. Salford LG, Brun A, Eberhardt JL, Persson BRR. Permeability of the blood brain barrier induced by $915 \mathrm{MHz}$ electromagnetic radiation; continuous wave and modulated at 8, 16, 50 and $200 \mathrm{~Hz}$. Bioelectrochem Bioenerg 1993;30:293-301.

41. Salford LG, Brun A, Sturesson K, Eberhardt JL, Persson BRR. Permeability of the blood brain barrier induced by 915 $\mathrm{MHz}$ electromagnetic radiation, continuous wave and modulated at 8, 16, 50 and $200 \mathrm{~Hz}$. Micros Res Tech 1994;27:53542.

42. Prato FS, Wills JM, Frappier JRH, Drost DJ, Lee TY, Shivers $\mathrm{RR}$, Zabel P. Blood-brain barrier permeability in rats is altered by exposure to magnetic fields associated with magnetic resonance imaging at 1.5 t. Micros Res Tech 1994;27:52834.

43. Lai H, Singh NP. Acute low intensity microwave exposure increases DNA single-strand breaks in rat brain cells. Bioelectromagnetics 1995;16:207-10.

44. Lai H, Singh NP. Single- and double-strand DNA breaks in rat brain cells after acute exposure to radiofrequency electromagnetic radiation. Int J Radiat Biol 1996;69:513-21.

45. Guy AW. Bioeffects of long-term exposure of animals. In: Klauenberg BJ, Grandolfo M, Erwin DN, editors. Radiofrequency radiation standards; biological effects, dosimetry, epidemiology, and public health policy. New York (NY): Plenum Press, 1995:311-26. Nato ASI series. Series A: life sciences 274.

46. Elder JA. Thermal, cumulative and life span effects and cancer in mammals exposed to radiofrequency radiation. In: Carpenter DO, Ayrapetyan S, editors. Biological effects of electric and magnetc fields; vol 2. San Diego (CA): Academic Press, 1994: 279-95.

47. Chou CK, Guy AW, Kunz LL, Johnson RB, Crowley JJ, Krupp JH. Long-term, low-level microwave irradiation of rats. Bioelectromagnetics 1992;13:469-96.

48. Repacholi MH, Basten A, Gebski V, Noonan D, Finnie J, Harris AW. Lymphomas in E $\mu$-Piml transgenic mice exposed to pulsed $900 \mathrm{MHz}$ electromagnetic fields. Radiat Res 1997; 147:631-40.

49. Salford LG, Brun A, Persson BRR, Eberhardt J. Experimental studies of brain tumour development during exposure to continuous and pulsed $915 \mathrm{MHz}$ radiofrequency radiation. Bioelectrochem Bioenerg 1993;30:313-8.

50. Chagnaud J-L, Després B, Veyret B. Effects of pulsed microwaves on the immune system and on chemically induced tumors in rats. In: Simunic D, editor. Biological effects relevant to amplitude modulated RF fields: proceedings of the
COST 244 workshop; September 1995, Kuopio. European Union, 1996:2-6. CEC-XIII-244/6/96.

51. Goldsmith JR. Epidemiologic evidence of radiofrequency radiation (microwave) effect on health in military, broadcasting and occupational studies. Int $J$ Occup Environ Health 1995; 1:47-57

52. Goldsmith JR. Epidemiological studies of radio-frequency radiation: current status and areas of concern. Sci Total Environ 1996; $180: 3$-8.

53. Bortkiewicz A, Zmyslony M, Palczynski C, Gadzicka E, Szmigielski S. Dysregulation of autonomic control of cardiac function in workers at AM broadcasting stations (0.738$1.503 \mathrm{MHz}$ ). Electro Magnetobiol 1995;14:177-91.

54. Bortkiewicz A, Gadzicka E, Zmyslony M. Heart rate variability in workers exposed to medium-frequency electromagnetic fields. J Auton Nerv Syst 1996;59:91 — 7.

55. Zhao Z, Zhang S, Zho H, Zhang S, Su J, Li L. The effects of radiofrequency $(<30 \mathrm{MHz})$ radiation in humans. Rev Environ Health 1994;10:213-5.

56. Bielski J. Bioelectrical brain activity in workers exposed to electromagnetic fields. Ann NY Acad Sci 1994;724:435-7.

57. Kalnins T, Krizbergs R, Romancuks A. Measurement of the intensity of electromagnetic radiation from the Skrunda radio location station, Latvia. Sci Total Environ 1996;180:51—6.

58. Kolodynski AA, Kolodynska VV. Motor and psychological functions of school children living in the area of the Skrunda radio location station in Latvia. Sci Total Environ 1996;180:87-93.

59. Szmigielski S. Cancer morbidity in subjects occupationally exposed to high frequency (radiofrequency and microwave) electromagnetic radiation. Sci Total Environ 1996;180:917.

60. Armstrong B, Thériault G, Guénel P, Deadman J, Goldberg M, Héroux P. Association between exposure to pulsed electromagnetic fields and cancer in electric utility workers in Quebec, Canada, and France. Am J Epidemiol 1994;140:805-20.

61. Rothman KJ, Chou CK, Morgan R, Balzano Q, Guy AW, Funch DP, et al. Assessment of cellular telephone and other radio frequency exposure for epidemiologic research. Epidemiology 1996;7:291-8.

62. Kaiser F. Amplitude modulated signals and non-linear oscillations: possible mechanisms for interaction of weak electromagnetic fields with biological systems. In: Simunic D, editor. Biological effects relevant to amplitude modulated RF fields: proceedings of the COST 244 workshop; September 1995, Kuopio. European Union, 1996:26-41. CEC-XIII-244/ $6 / 96$

63. Chiabrera A, Bianco B, Moggia E, Tommasi T. Basal cell metabolism and sensitivity to low-intensity AM RF fields. In: Simunic D, editor. Biological effects relevant to amplitude modulated RF fields: proceedings of the COST 244 workshop; September 1995, Kuopio. European Union, 1996:716. CEC-XIII-244/6/96.

64. Philippova TM, Novoselov VI, Alekseev SI. Influence of microwaves on different types of receptors and the role of peroxidation of lipids on receptor protein shedding. Bioelectromagnetics 1994;15:183-92.

Received for publication: 23 December 1997 